\title{
Henri Meschonnic: o traduzir e o poema, um processo de criação contínuo
}

\author{
Henri Meschonnic: The translate and the POEM, A Continuous \\ PROCESS OF CREATION
}

Marie-Hélène Paret Passos*

Resumo: Nesse artigo, circunscrevo a reflexão em torno do processo de criação literária e analiso manuscritos autógrafos do acervo Henri Meschonnic, poeta, ensaísta e tradutor da Bíblia. Embaso minha reflexão sobre a análise de um conjunto de manuscritos, referentes à gênese de um ensaio teórico, de poemas e de um processo tradutório. Apresentarei um recorte de três exemplos para mostrar que é possível tentar entender como funciona o processo de criação do autor em seu ato de escritura: reflexivo e teórico, na textualização do ensaio Poética do traduzirir, poético e tradutório, no traduzir da Bíblia hebraica. Tentarei esboçar uma primeira reflexão sobre o recurso à crítica genética para analisar o que um texto faz e como ele faz, o que Henri Meschonnic chama atividade. Algo que não concerne ao sentido, mas ao ritmo. O ritmo como a organização do movimento da fala na escritura, que constrói um sistema de discurso, próprio ao sujeito, e que tem uma atividade. Ele age. Palavras-chave: Henri Meschonnic. Crítica genética. Ritmo.

Abstract: In this article, I circumscribe the reflection about the process of literary creation and I analyze manuscripts of the Henri Meschonnic collection, poet, essayist and translator of the Bible. I ground my reflection on the

\footnotetext{
* Professora do PPGL/PUCRS na área de Escrita Criativa. Doutorado defendido em 2008 na UFRGS. Desenvolve pesquisa em Crítica Genética e Tradução Literária. No Pós-doutorado (CAPES), que realizou em 2015/2016 na Université Sorbonne Nouvelle Paris 3, dedicou-se à pesquisa no acervo "Henri Meschonnic". (PNPD/CAPES). Contato: marie-helene@pucrs.br.
} 
analysis of a set of manuscripts that refer to the genesis of a theoretical essay, poems and a translation process. I will present a clipping of three examples to show that it is possible to try to understand how works the process of creation of the author in his act of writing: reflective and theoretical, in the textualization of the essay Poétique du traduire; poetic and of the translation process, in the translation of the Hebrew Bible. I will try to sketch a start reflection on the use of genetic criticism to analyze what a text does and how it does, what Henri Meschonnic calls activity. That is to say, that does not concern to the sense but to the rhythm. The rhythm as the organization of the movement of speech in writing, that builds a system of discourse, specific to the subject, and that has an activity. It acts.

Keywords: Henri Meschonnic. Genetic criticism. Rhythm.

O ato criador, em todos os campos do saber, e em todos os campos das artes, é a atividade mais finalizada que o cérebro humano é capaz de produzir. É motivada por uma intenção, muitas vezes apenas intuída, embora imprescindível para desencadear um processo árduo que, para redundar em uma obra, deve ser sustentado pela tenacidade e um trabalho incessante de construção progressiva. Criar é uma competência que envolve a capacidade de aventurar-se no desconhecido. Pois, é somente ao desbravar o desconhecido que se faz formas novas existirem. Eis o princípio do trabalho de criação. E, embora não se negue à inspiração um papel, tão fulgurante quanto pontual, sem o burilar de quem cria, a obra não se forma.

O propósito da crítica genética é analisar esse trabalho de criação, o burilar, qualquer que seja o campo em que este acontece.

Nesse artigo, circunscrevo a reflexão em torno do processo de criação literária e analiso manuscritos autógrafos do acervo Henri Meschonnic ${ }^{1}$, poeta, ensaísta e tradutor da Bíblia ${ }^{2}$. Embaso minha reflexão sobre a análise de um

\footnotetext{
${ }^{1} \mathrm{O}$ acervo "Henri Meschonnic" é conservado no Institut Mémoire de l'Edition Contemporaine - IMEC <www.imec-archives.com>. O poeta depositou seu acervo no IMEC em 2007.

${ }^{2}$ Henri Meschonnic traduziu quatro dos cinco livros do Pentateuco. Au commencement (2002), Les noms (2003), Et il a appelé (2005), Dans le désert (2008), todos publicados pela editora Desclée de Brouwer.
} 
conjunto de manuscritos, referentes à gênese de um ensaio teórico, de poemas e de um processo tradutório. Apresentarei um recorte de três exemplos para mostrar que é possível tentar entender como funciona o processo de criação do autor em seu ato de escritura: reflexivo e teórico, na textualização do ensaio Poética do traduzir, poético, em dois poemas e tradutório, no traduzir da Bíblia hebraica. E, tentarei esboçar uma primeira reflexão sobre o recurso à crítica genética para analisar o que um texto faz e como ele faz, o que Henri Meschonnic chama atividade.

Percorrer o acervo Henri Meschonnic é constatar que a obra acabada construiu-se no decorrer de mais de três décadas (1970-2008). Por mais de trinta anos, o poeta teorizou o traduzir a partir de sua prática tradutória da Bíblia hebraica e a partir da criação de seus poemas, fazendo com que teoria e prática participem de um único movimento criador. Por outro lado, ao teorizar o traduzir, é toda a teoria da linguagem que ele se empenhou a teorizar e renovar.

\section{Poética do Traduzir e Processo de Criação}

Para Henri Meschonnic, pensar a teoria da linguagem implica pensar o traduzir pelo fato de ele ser o ponto fraco dessa teoria por ser pensado à parte e, ainda, por ser pensado na confusão da língua e do discurso. No fazer meschonniciano, pensar é inventar o seu pensamento. E, inventar um pensamento é criar, isto é, estar na poética.

Uma abordagem genética, convém frisar, não pretende desvendar o processo mental que deu origem ao produto criado. Ela se debruça sobre rastros $^{3}$ e restos materiais desse processo. No entanto, convém salientar que a existência de rastros materiais já não é condição sine qua non para iniciar um estudo genético. No Brasil e no Exterior, geneticistas embasam suas pesquisas sobre documentos que não são diretamente documentos genéticos, isto é, que não portam as marcas de uma elaboração processual, mas que podem testemunhar um processo de criação. Por exemplo, a correspondência, os diários, as marginálias, as entrevistas etc.

${ }^{3}$ Rasuras e movimentos de escritura: acréscimo, supressão, deslocamento, substituição. 
Abordar o processo de criação de uma obra literária, ficcional ou não, pelos pressupostos da crítica genética, implica debruçar-se sobre uma escritura (um fazer) e não sobre uma obra publicada (um feito) posto que o processo de criação não é acessível diretamente. Nesse sentido, a abordagem genética concentra-se na reconstrução de um movimento escritural a partir dos rastros que deixou nos suportes utilizados. O cerne analítico é a atividade do processo criador, não para ter o privilégio de desvendar os "porquês" da criação, mas para refletir sobre um como. Como foi feita a obra. Como ela faz o que faz, para retomar a indagação de Henri Meschonnic, em sua teorização de uma poética como epistemologia da escritura, isto é, visando um conhecimento da escritura e da literatura "en tant que cette connaissance est dans un rapport nécessaire avec une pratique"4 (MESCHONNIC, 1972, p. 25).

O almejado no presente estudo genético passa pela análise do fazer meschoniciano, e visa delinear como a sua teorização, na relação com a sua prática, manifesta-se no seu processo escritural. Em outras palavras, almejo analisar se, e como, na parte material do processo de criação, o fazer de Henri Meschonnic está em consonância com o seu dizer teórico.

\section{Manuscritos de Poética do Traduzir}

Apresento aqui a transcrição de algumas páginas da primeira versão do manuscrito autógrafo ${ }^{5}$ (1987), para analisar como se transforma o modo de Henri Meschonnic significar o seu discurso sobre o traduzir. No manuscrito, a introdução começava com subtítulo: «Parce que l'expérience est première » (Porque a experiência é primeira), substituído por: "Começando pelos princípios". A intenção é de inscrever o seu trabalho, e a sua reflexão (o livro), em uma continuidade e, de entrada, dar à tradução o papel único, ignorado e revelador do pensamento da linguagem e da literatura. (MESCHONNIC, 2010, p. XVIII).

\footnotetext{
4 "Sendo que esse conhecimento está em uma relação necessária com uma prática" (tradução nossa).

${ }^{5}$ Referência do documento no IMEC: MCN 45.
} 
pour situer

d'où ce titre ce livre, qui essaie de rassembler l'essentiel, le point de vue de ce que j'appelle la produits, la traduction,

poétique, sur l'acte de traduire, et sur ses résultats divers, les traductions ${ }^{6}$

Nesse primeiro excerto, a primeira substituição de « qui essaie de rassembler l'essentiel » (que procura agrupar o essencial) por « pour situer » (para situar) visa inserir o seu discurso próprio dentro do grande discurso sobre tradução, ao enunciar que o gesto crítico é indispensável à teorização da prática constituída pelo « ato de traduzir ». Ato que passa a instaurar uma distinção entre um fazer relativo ao verbo traduzir e um produto desse fazer, a tradução. $\mathrm{Na}$ segunda linha, passamos de « résultats divers » (resultados diversos) a «produits» (produtos). De início, estamos na textualização da introdução, e Henri Meschonnic deixa claro que nessa poética, que ele está pensando, logo, que está criando, existe um fazer e um feito. É patente que é nesse fazer que se situa o fato de pensar a poética tradutória.

Na página seguinte do manuscrito, vemos outra frase significativa:

\section{plutôt}

Je dis poétique du traduire, que "poétique de la traduction", pour

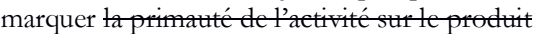
qu'il s'agit d'abord d'analyser l'activité, à travers ses produits

à travers

Para melhor visualização da frase decomponho as duas camadas de escritura, sendo a primeira ocorrência:

Je dis poétique du traduire, pas " poétique de la traduction», pour marquer la primauté de l'activité sur le produit.

6 "Daí este livro, para situar o ponto de vista do que chamo a poética, sobre o ato de traduzir, e os seus produtos, a tradução, as traduções” (MESCHONNIC, 2010, p. XVIII).

7 “Digo poética do traduæiri, mais do que 'poética da tradução', para marcar que se trata da atividade, por meio de seus produtos” (MESCHONNIC, 2010, p. XIX). 
Ao voltar no já escrito, a frase é ainda modificada duas vezes:

- 1 Je dis poétique du traduire, plutôt que « poétique de la traduction », pour marquer qu'il s'agit d'abordd'analyser l'activité, à travers ses produits.

- 2 Je dis poétique du traduire, plutôt que « poétique de la traduction», pour marquer qu'il s'agit de l'activité, à travers ses produits.

As alterações, na segunda parte da frase, modificam um posicionamento crítico que fazia da tradução um produto subalterno, implicitamente inoperante para a tarefa almejada. $\mathrm{Na}$ (re)leitura do já escrito, o scriptor ${ }^{8}$ cancela a palavra " primauté » (primado) para deixar as palavras, « atividade » e " produto ", em um mesmo patamar de importância. Em um primeiro momento, o poeta tradutor expressa que a atividade (o traduzir) prevalece ao produto (a tradução), enfatizando assim o valor do fazer sobre o feito. No entanto, na leitura inerente à escritura, e, sempre no movimento do pensar, ele modifica e suprime a palavra «primauté » (primado), palavra que implicava uma hierarquia.

Esse primeiro jorro, provavelmente, não poderia ser diferente, sendo que Henri Meschonnic, incessantemente, pensou a atividade do sujeito ${ }^{9}$ como organização de seu discurso. Organização que é o cerne de sua teoria do ritmo $^{10}$ e da linguagem. E, ela implica uma atividade que "suppose que le langage fait quelque chose en même temps qu'il dit"11 (MESCHONNIC, 1982, p. 63). Logo, é essa atividade que há de ser analisada antes de traduzirse um texto, posto que ela é modo de significar - de organizar os elementos do discurso - específico de um sujeito, e não de outro. Portanto é singular por natureza em seu processo de criação e sua atividade passa a fazer algo que não concerne somente ao sentido (o signo), que ultrapassa o sentido, e se

${ }^{8}$ Utilizo o conceito de scriptor tal o teorizou Philippe Willemart (2014).

${ }^{9}$ No sentido da subjetivação máxima de um discurso.

${ }^{10}$ Todo o pensamento teórico-crítico de Meschonnic tem como substrato uma nova teorização do ritmo na linguagem. Para ele: "se a criação de sentido é uma atividade do sujeito e se o ritmo é uma organização do sentido no discurso, o ritmo é necessariamente uma organização ou configuração do sujeito em seu discurso" (MESCHONNIC, 1982, p. 71, tradução nossa).

11 "supõe que a linguagem faz algo ao mesmo tempo em que diz" (tradução nossa). 
manifesta (se ouve), por exemplo, na constituição de séries prosódicas significantes.

Ainda na introdução, na folha 7 do manuscrito, examinemos o acréscimo marginal que se insere após a frase: “Je n'énonce pas ici des vérités. Seulement une stratégie pour un enjeu" ${ }^{\prime 2}$.

Par stratégie j'entends un mode d'action d'une théorie en vue de la réalisation d'un projet. Le projet, faire la traduction comme une poétique.

A frase acrescida é modificada em:

Par stratégie j'entends un mode d'action d'une pensée organisée pour réaliser un projet. Le projet, faire la traduction comme une poétique ${ }^{13}$.

A introdução do sintagma "pensée organisée » (pensamento organizado) impõe a necessidade de um pensamento produzido de uma determinada maneira, diferentemente da noção de teoria que, não raro, limita as veleidades do pensar (do criar) em prol da reprodução de algo já dito, já pensado, assim, exterior ao sujeito. Produzir um pensamento organizado é, para Henri Meschonnic, a maneira de produzir uma teoria, isto é, de refletir sobre o modo de ação desenvolvido para realizar, no caso que nos ocupa, uma tradução, ou seja, refletir sobre o desconhecido. Essa substituição participa da organização de um modo de significar: " pensée organisée pour réaliser ", uma acentuação final gradativa no eco das palavras, respectivamente: [se], [ze], [ze]. Dessa forma está salientada uma intensidade semântica que solidariza o grupo « pensée organisée » cujo resultado redunda na realização de algo (projeto). Uma realização que não está somente dita no verbo " réaliser » mas que também está sendo cumprida pelo encadeamento prosódico. A série continua e entra em consonância com palavra « projet » e a sua repetição na frase seguinte. E ainda, o segundo $p$ (pour) relança o primeiro de

\footnotetext{
12 "Não enuncio aqui verdades. Somente uma estratégia para uma aposta" (MESCHONNIC, 2010, p. XIX).

13“Por estratégia, entendo um modo de ação de um pensamento organizado para realizar um projeto" (MESCHONNIC, 2010, p. XIX).
} 
" pensée ». O encadeamento prosódico do todo dá sua forma ao sentido e enfatiza que sem a ação do pensamento ativo não existe concretização.

No conjunto dos manuscritos, são praticamente sistemáticas as substituições da palavra «traduction » por « traduire », por exemplo:

du traduire

Il y a encore une troisième raison pour parler de poétique de la La poétique n'est pas une science $[\ldots]^{14}$ du traduire

Essa necessidade de substantivar o verbo visa salientar a atividade, o fazer da criação que deve sustentar o traduzir, dado que essa atividade é a organização de seu discurso pelo sujeito. Esse ponto é fundamental, uma vez que nele se encontram o traduzir e o escrever, ambos produtores de discursos próprios. Daí a necessidade de perenizar o primado dessa atividade, cancelado em outra ocasião, como já vimos. De fato, para Henri Meschonnic, a atividade é primordial, porque sustenta a ação da linguagem sobre quem enuncia, a ação de quem enuncia sobre a linguagem e a ação sobre o outro. $\mathrm{E}$, é nesse movimento ativo, recíproco, dinâmico e criador que Henri Meschonnic inscreve a sua definição do poema: "Digo poema para toda a literatura, não somente no sentido restrito habitualmente para a 'poesia' por oposição a 'romance' “ (MESCHONNIC, 2010, p. XVIII).

\section{O Traduzir da Bíblia Hebraica}

"É enquanto tradutor que eu teorizo" (MESCHONNIC, 2010, p. 41). Ou ainda "Pois só há teoria através da prática" (MESCHONNIC, 2010, p. 41), são frases que, incansável, Henri Meschonnic repetia. Suas traduções refletem o seu pensar teórico, ele-mesmo nutrido pela sua prática tradutória e pela escritura de seus poemas:

\footnotetext{
14 "Há ainda uma terceira razão para falar de poética do traduzir" (MESCHONNIC, 2010, p. 4). "A poética do traduzir não é, pois, uma ciência [...]" (MESCHONNIC, 2010, p. 5).
} 
Un poème pour, moi, ne raconte pas d'histoire. Mes poèmes sont les condensations du sens de a vie. C'est pourquoi ils tiennent moins de place que le reste de mon travail, mais c'est eux qui me font traduire la Bible comme je traduis, qui me font penser le langage, la poésie, la traduction comme je fais ${ }^{15}$ (MESCHONNIC, 2006, p. 8).

Para Henri Meschonnic, a Bíblia é o terreno idôneo de experimentação e teorização do traduzir (MESCHONNIC, 1973, p. 406). A especificidade do texto bíblico, em seu modo de significar, é a de ser uma oralidade:

Uma oralidade codificada como em nenhuma outra parte, não é somente uma estilística das estruturas e dos desvios, nem uma semiótica das ações que podem caracterizar modos de significar que têm seus discursos, é uma poética do ritmo que também é necessário - de que a tradução, com seus riscos, suas resistências, não pode ser outra coisa senão que experimentação. (MESCHONNIC, 2010, p. 231).

Portanto, um primado do ritmo. Portanto, um terreno idôneo para acolher a sua teorização crítica em uma escritura e não em uma reprodução, pois, "traduzir textos bíblicos significa incluir à linguagem poética moderna essa linguagem da Bíblia que séculos de racionalismo, em francês, haviam mascarados" (MESCHONNIC, 1970, p. II, tradução minha).

Dessa forma, o texto bíblico apreendido como enunciação impõe uma reflexão e uma prática outra. A prática de um ritmo inscrito no texto de forma exemplar (nos acentos). A reflexão acerca do efeito teórico desse ritmo significante sobre a linguagem e a tradução.

No texto bíblico existe, no mais alto grau, algo outro a ser traduzido, que está além do único sentido das palavras. O que implica um processo tradutório no qual age uma atividade, tal Henri Meschonnic a definiu: o modo de significar próprio ao tradutor. É nesse modo de significar que se dá a invenção do discurso próprio, isto é, que se dá a criação. É o cerne do

\footnotetext{
15 “Um poema para mim, não conta histórias. Meus poemas são as condensações do sentido da minha vida. É por isso que ocupam menos espaço que o resto do meu trabalho, mas são eles que me fazem traduzir a Bíblia como traduzo, que me fazem pensar a linguagem, a poesia, a tradução como eu faço" (tradução nossa).
} 
traduzir-escrever, em que traduzir e escrever ligam suas atividades numa relação, fazendo do traduzir a atividade que acresce, e não mais a atividade que retira. É o ganho da invenção do discurso próprio, da criação que se aventura ${ }^{16}$ : "Eu me escrevo nos textos bíblicos ao traduzi-los" (MESCHONNIC, 2010, p. 270), diz o poeta, e arrisca-se rumo ao desconhecido.

\section{No atelie do poema e do traduzir-escrever}

Em sua prática do escrever dentro e por um traduzir (MESCHONNIC, 1973, p. 207), Henri Meschonnic estuda o funcionamento do texto bíblico no intuito de traduzir-escrevê-lo, pois, para ele: “Traduire n'est traduire que quand traduire est un laboratoire d'écrire"17 (MESCHONNIC, 1999, p. 459). Adentramos agora o ateliê do poeta para examinar, a partir da análise de dois exemplos de manuscritos ${ }^{18}$ da tradução, como funciona seu processo de criação tradutório.

\section{(Gênesis I,1-5)}

“Le manuscrit est l'atelier" "19, (MESCHONNIC, 2002, p. 115), escreveu Henri Meschonnic no quadro de uma reflexão sobre uma poética própria ao manuscrito, e ainda: "Le manuscrit est l'état qui permet d'accéder à une poétique du texte dans son écriture, non comme graphie, bien sûr, mais comme rythme" ${ }^{20}$. (MESCHONNIC, 2002, p. 118). Nessa frase, ele se obriga

\footnotetext{
${ }^{16}$ Concernente à criação do verbo embabelar, que veremos mais adiante, Henri Meschonnic escreveu: "aventurei o verbo embabelar" (MESCHONNIC, 2010, p. 263).

17 “'Traduzir só é traduzir quando traduzir é um laboratório de escrever" (tradução nossa).

${ }^{18}$ Referência dos documentos no IMEC: MCN 70.

19 “O manuscrito é o ateliê"” (tradução minha). Em 1985, Henri Meschonnic analisou vários manuscritos de Victor Hugo no quadro de sua participação da Jornada de Estudos, organizada na Universidade Paris VIII, cujo tema foi: "Os manuscritos de Victor Hugo”. Esse trabalho redundou na publicação, em 2002, do livro Hugo, la poésie contre le maintien de l'ordre.

20 “'O manuscrito é o estado que permite acessar uma poética do texto em sua escritura, não como grafia, claro, mas como ritmo" (tradução nossa).
} 
a especificar a sua apreensão da palavra écriture, posto que, no francês, a palavra possui somente uma forma, enquanto no português dispõe de duas: escrita e escritura. Portanto, ao especificar que o manuscrito permite acessar um certo estado de escritura ${ }^{21}$, e que essa escritura é ritmo, ele está em um pensamento genético, pressupondo que o manuscrito permite acessar algo que a escrita fixada do texto publicado não permite.

A segunda utilização da palavra ateliê aparece nos textos introdutórios a suas traduções bíblicas a partir da tradução dos Salmos ${ }^{22}$, em 2001, nos parágrafos intitulados «Les notes » (As notas). Essas numerosas notas que seguem as traduções não visam à erudição, elas são presentes "pour faire participer à l'atelier du poème, qui est l'atelier du traduire"; "elles ne sont faites que pour ouvrir l'atelier du poème, l'atelier du traduire"; "les notes ne sont là que pour faire partager à qui va lire l'atelier du traduire et du poème"23.

Contudo, é patente que nessa segunda utilização da palavra ateliê, dissociada do estado manuscrito, Henri Meschonnic não visa mostrar uma escritura (um ritmo). Ele não se ocupa do processo de criação em si mas julga fundamental compartilhar seus bastidores. Daí, escolhe apresentar o caminho de uma reflexão que se deu durante o processo tradutório. Dessa forma, as notas tornam-se solidárias do poema. Embora ausentes desse poema, as notas dão conta de um fazer que sustentou a escritura tradutória. A uma pergunta sobre essas notas, o poeta tradutor explicava: "Les notes de ce livre ne sont pas du tout des notes d'exégèse ou d'historien que je n'aurais fait que recopier. J'ai voulu donner au lecteur le moyen de participer à l'atelier du traduire qui est l'atelier du poème. J'ai donc exposé le dossier" ${ }^{24}$ (VÉRITÉ

${ }^{21}$ Ver nota 9.

${ }^{22}$ MESCHONNIC, Henri. Gloires. Traduction des Psaumes. Paris, Desclée de Brouwer, 2001.

23 "para fazer participar do ateliê do poema que é o ateliê do traduzir" (MESCHONNIC, 2002, p. 21, tradução minha); "são feitas unicamente para abrir o ateliê do poema, o ateliê do traduzir" (MESCHONNIC, 2001, p. 51, tradução nossa); "as notas são unicamente para fazer compartilhar a quem vai ler o ateliê do traduzir e do poema." (MESCHONNIC, 2003, p. 28, tradução nossa).

24 "As notas desse livro não são notas de exegese ou de historiador que eu teria somente copiado. Eu quis dar ao leitor o meio de participar do ateliê do traduzir que é o ateliê do poema. Então, expus o dossiê" (VÉRITÉ..., 2001, p. 22, tradução nossa). 
DE LA BIBLE, 2001, p. 20). Para o geneticista, o dossiê em questão tem um som assaz genético, mas não convém extrapolar o propósito do poeta.

No entanto, a resposta acima revela que as notas resultam de um processo de escritura, como o texto traduzido, já que o tradutor especifica que elas não foram copiadas, o que implica que elas foram criadas em um processo escritural simultâneo ou concomitante ao processo tradutório. O fato de ligar o traduzir e o poema em um mesmo ateliê sugere claramente que o traduzir implica o escrever, e, logo, o criar. As notas são explicativas e elucidativas na medida em que revelam dificuldades encontradas, assim como soluções escolhidas para resolvê-las. Todavia, não se limitam a explicar, elas apresentam uma reflexão analítico-comparativa de soluções escolhidas por outros tradutores do texto bíblico. Dessa forma, o leitor acessa informações que lhe possibilitam uma posição crítica. Assim, o intuito que faz o autor abrir o seu ateliê visa dar acesso à reflexão que sustentou a escolha tradutória: "Dans ces notes, chaque fois qu'il y a un problème prosodique ou rythmique, je le signale, ou chaque fois qu'il y a un problème de traduction" 25 (MESCHONNIC, 2002, p. 22).

Examinemos o primeiro exemplo, a tradução do Gênesis (I,2). A transcrição diplomática da segunda versão autógrafa ${ }^{26}$ mostra uma primeira fase genética de um processo tradutório que aconteceu provavelmente em 1972. O manuscrito não apresenta data, contudo, esse primeiro estado da tradução foi publicado em 1973, no livro Pour la Poétique II.

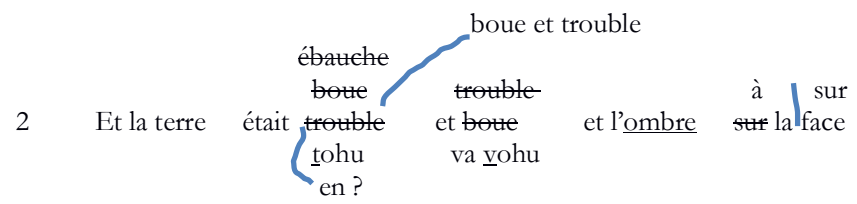
remous d'un gouffre du de l'eau Et le souffle de Dieu recouvre la face

Segunda versão autógrafa (Gênesis I, 2) (1972)

25 "Nessas notas, cada vez que há um problema prosódico ou rítmico eu o assinalo, ou cada vez que há um problema de tradução" (tradução nossa).

${ }^{26}$ Referência do documento no IMEC: MCN 113. 
Podemos observar o intenso trabalho de reescritura em torno das palavras «trouble » (turva) e « boue » (lama) para traduzir o hebraico « tohu / vavohu ». Vemos que uma das soluções tentadas pelo tradutor foi, inclusive, de conservar o sintagma hebraico. Contudo, o tradutor escolheu, para a primeira publicação, a combinação: «Et la terre était boue et trouble » (E a terra era lama e turva). A tradução dos cinco primeiros versículos do Gênesis foi publicada em 1973 e apresentada como "uma experiência e uma tentativa de tradução" (MESCHONNIC, 1973, p. 450 - tradução minha). Era acompanhada de um texto crítico-analítico que almejava, também, explicar e comentar as escolhas feitas na tradução para ilustrar a relação entre prática e crítica. Portanto, desde 1973, já estava acessível uma primeira forma de ateliê, no qual o tradutor já estava a burilar o problema levantado pela tradução de « tohu /vavohu ». Um problema paradigmático por apresentar a especificidade da linguagem bíblica, como materialidade, dicção, prosódia e ritmo inseparáveis do sentido. Para ressignificar o não linguístico, a solução encontrada foi, por sua vez, não linguística. De fato, o tradutor introduziu a inscrição de um espaço em branco entre « tohu » e « vavohu », essa expressão semanticamente obscura, mas cuja modulação semântica é dada pelo "conflito entre grupo sintáxico, grupo prosódico e grupo rítmico” (MESCHONNIC, 1973, p. 451). O ritmo, marcado pela presença de um acento disjuntivo ${ }^{27}$ após « tohu », necessita que, na oralização do texto, « tohu » seja separado do resto do grupo e lido em um único sopro com o verbo que o precede, « hayta », ficando a leitura: « haytatohu ». O acento disjuntivo introduz uma pausa entre «tohu » e "vavohu ». São estas as condições que o tradutor procurou reproduzir semântica e ritmicamente. Sendo, a primeira solução adotada: " était boue et trouble ». No que concerne ao sentido do sintagma, Henri Meschonnic, como o explica na nota (MESCHONNIC, 1973, p. 432, 451), valeu-se de comentários da tradição hebraica.

Na mesma pasta que contém o manuscrito dessa tradução, encontrei uma série de anotações manuscritas sobre pequenas folhas quadradas, usadas

\footnotetext{
${ }^{27} \mathrm{O}$ texto bíblico que Meschonnic traduz é o texto massorético, que contém os acentos rítmico-prosódicos (te’amim). (KITTEL, Rudolf (Ed.). Bíblia hebraica. 11. ed. Stuttgart: Privilegierte Württembergische Bibelanstalt, s.d. [7.ed. 1951].
} 
como espécie de fichas, em que o tradutor escreve a sua pesquisa semântica sobre o binômio problemático. Apresento a transcrição diplomática de algumas dessas fichas:

\author{
désert et désordre \\ désert et désolation \\ ds le texte: effet d'incantation \\ 4 fois la même voyelle accentuée \\ tohu - vohu - hoshekh - tehom \\ de peur d'horreur \\ une masse \\ une glaise \\ informe et morte \\ informe et mort \\ borreur et vide \\ une masse de mort \\ sans vie, un chaos \\ amorphe $=$ matière informe \\ sans vie et vide \\ mouvante et vide \\ épouvante et vide \\ sans forme et mort
}

Vemos, nessa primeira sequência, uma lista de palavras refletindo uma procura da prosódia, no intuito de construir uma significância e um efeito de encantação: «ds le texte: effet d'incantation/4 fois la même voyelle accentuée/ tohu - vohu - hoshekh - tehom » (no texto: efeito de encantação: 4vezes a mesma vogal/ tohu - vohu - hoshekh - tehom). Desta forma, essa procura da tradução idônea para o binômio invade o espaço das anotações de pesquisa e, listas de pares de palavras atestam que o processo tradutório e criativo não se limita ao ato espacial e temporalmente circunscrito à escritura tradutória na folha branca. Esse movimento é um só movimento, sustentado pelo pensamento que se foca às vezes na pesquisa, às vezes na leitura de outras 
traduções, às vezes no trabalho de reescritura, ou seja, em todos os recursos dos quais o tradutor lança mão, sem nunca excluir a criação.

No que concerne à escritura do ritmo, o tradutor encontrou, na inclusão de espaços brancos no versículo, a maneira de marcar a disjunção das palavras do binômio, isto é, ele encontrou a forma de inscrever o ritmo do texto bíblico. Era o que Henri Meschonnic almejava realizar quando se lançou na tradução da Bíblia e anunciou a façanha, no texto que antecede a primeira tradução Les Cinq Rouleaux (Os Cinco Rolos): 'J'ai voulu rendre, et je crois qu'on ne l'avait jamais fait, les accents et les pauses dont la hiérarchie complexe fait la modulation du verset biblique, son rythme et parfois même son sens"28 (MESCHONNIC, 1970, p. 15).

$\mathrm{O}$ acesso aos manuscritos permite constatar como o poeta tradutor, de fato, fez o que ele se propunha fazer, e permite também constatar como ele fez.

Em outras fichas de notas, podemos ler:

Tohu et Bohu Rachi - commentateur fr du XII s.

"signifie étonnement, stupéfaction" $\rightarrow=$ épouvante

il note l'effet produit et non le sens

en français $=$ estordison

bohu signifie vide et solitude

"l'homme est saisi de stupéfaction et d'horreur en présence du vide."

tohu vavohu

Il s'en faut de beaucoup que le sens de ces mots soit précis

Opinions divisées

Ce qui est clair $\rightarrow$ "la matière informe dont est créé la terre était tout entière en l'état de chaos, sans forma ni ordre."

Nessas notas, podemos perceber que a procura de uma solução pereniza-se e leva o tradutor a pesquisar na tradição exegética hebraica. No

\footnotetext{
28 “Eu quis reproduzir, e acredito que nunca havia sido tentado, os acentos e as pausas cuja hierarquia complexa faz a modulação do versículo bíblico, seu ritmo e às vezes até seu sentido" (tradução nossa).
} 
exemplo citado, vemos que ele consultou os comentários de Rashi ${ }^{29}$, cuja explicação do binômio é: "signifie étonnement, stupéfaction » (significa espanto, estupefação), o que provoca o seguinte comentário do tradutor: «il note l'effet produit et non le sens » (ele nota o efeito produzido e não sentido) e « bohu signifie vide et solitude » (bohu significa vazio e solitude), o que faz Rashi concluir: «l'homme est saisi de stupéfaction et d'horreur en présence du vide. » (o homem é tomado de estupefação e de horror em presença do vazio). É patente que a reprodução desse binômio provocou um denso trabalho de pesquisa, posto que para Meschonnic: "le rythme de la traduction doit être autonome, senti et jugé en français, mais fidèle, par l'organisation de toutes les rencontres des mots, au goût de l'original" 30 (MESCHONNIC, 1970, p. 17). A análise dos rastros encontrados nos manuscritos confirma que o discurso teórico de Henri Meschonnic, visando uma poética do traduzir, está em total coerência com o seu processo tradutório (traduzir-escrever). Parece claro que é essa coerência que ele pretendia mostrar ao abrir a seu ateliê. É inegável que, para o leitor, o acesso aos bastidores das traduções apresentados nas notas participa da emergência dessa coerência. É inegável, também, que o acesso aos manuscritos permite visualizar rastros de um processo que, uma vez postos em relação para reinvesti-los de sentido, tornaos ferramentas analíticas de um processo de criação. Ferramentas com as quais se adentra o mesmo ateliê sob outro ângulo, e que permitem mostrar como o poeta procura fazer o que diz.

Quando Henri Meschonnic retoma o trabalho, em 2001, conforme as datas inscritas no manuscrito autógrafo ${ }^{31}$ (Figura 1), podemos ver que o intenso trabalho de reescritura em torno do mesmo grupo persiste. Nessa segunda publicação, o texto muda e as modificações têm o amparo de numerosos anos de pesquisa e de prática. As notas são revisadas e reduzidas em relação à primeira publicação (1973).

\footnotetext{
${ }^{29}$ Rabbi Chlomo Its'haqi - Rachi (1040-1105), foi o maior comentarista da Bíblia hebraica. Meschonnic utilizou: Le Commentaire de Rachi sur le Pentateuque. 2 vol. Comptoir du livre du Keren Hasefer, Paris, 1957.

30 “O ritmo da tradução deve ser autônomo, sentido e julgado em francês, mas fiel, pela organização de todos os encontros de palavras, ao gosto do original” (tradução nossa).

${ }^{31}$ Referência do documento no IMEC: MCN 70.
} 


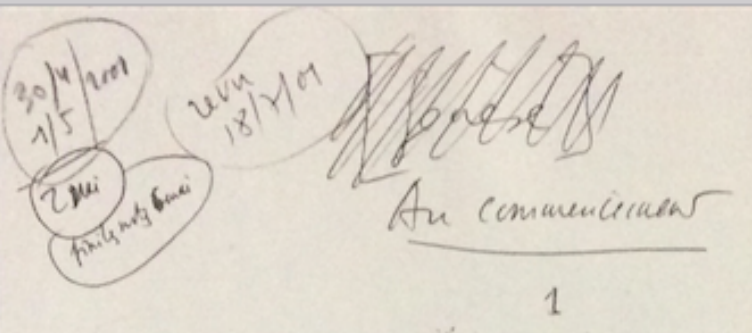

1 An canmenarar an que bien ba a crée

$$
\text { Le cal ortane }
$$

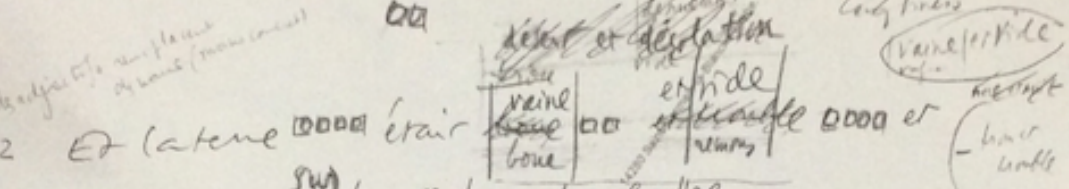

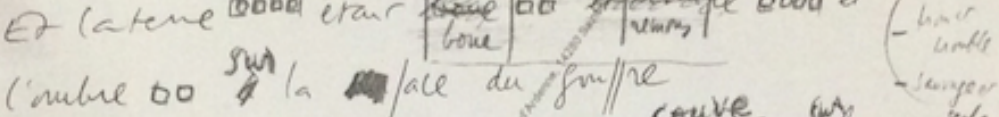

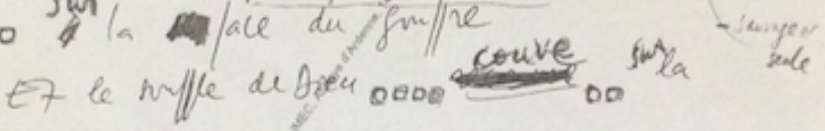

Anace de l'ear

3 ET Dien a dir oo fill pair la lamière

E-il to en la lamiere

lomlue

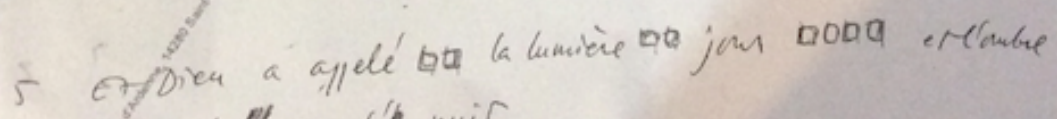
Ga il Va ayeléf mir

Fonte: MSC 70.

Figura 1 - Folha 1 versão autógrafa 4 Gênesis (I, 1-5) 
O segundo versículo (Figura 2) apresenta numerosas reescrituras à procura de uma solução satisfatória para a tradução do binômio « tóhu / vavóhu».

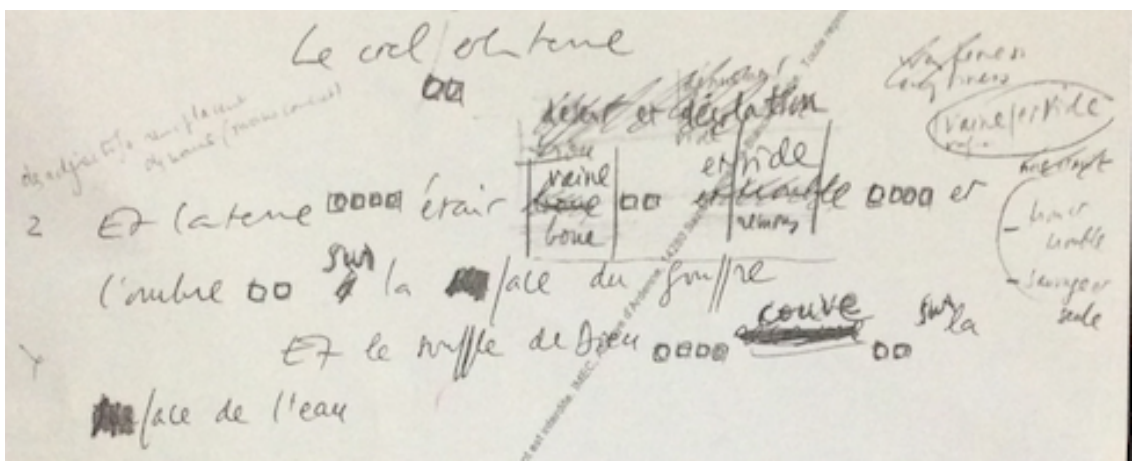

Fonte: MSC 70.

Figura 2 - Folha 1 versão 4 do manuscrito de tradução do Gênesis. Versículo 2

Na nota 2, Henri Meschonnic (2002, p. 244), escreveu: "Dans une première version, je traduisais 'boue et trouble" 32 . É o que podemos ler (Figura 2) sob as rasuras. O teor da nota, de um lado, faz adentrar o ateliê, do outro, explica o que o tradutor procurava alcançar a partir de sua análise do texto hebraico. Ele explica que « tóhu / vavóhu »é um binômio prosódico cuja forma de significar sustenta o sentido. Essa forma de significar é conferida pelos acentos hebraicos (te'amim), que indicam como deve ser lido o grupo significante em relação às palavras que o antecedem e o seguem. O sentido remete ao informe primordial. Assim sendo, após uma interrupção de vinte

\footnotetext{
32 “Numa primeira versão, eu traduzia 'lama' e 'turva' “ (tradução nossa). Convém mencionar que Henri Meschonnic trabalhou provavelmente na primeira versão no início da década de 1970, posto que ela foi publicada em 1973 no livro Pour la Poétique II. Portanto, é possível dizer que o tradutor retomou o trabalho tradutório no mesmo manuscrito, em 2001 (vemos a data na Figura 1), ou seja, pelo menos vinte e oito anos depois.
} 
e oito anos entre os dois períodos de trabalho, vemos que, de certa forma, uma continuidade instala-se, pois é o mesmo tipo de trabalho que (re)começa em torno do grupo problemático. No entanto, a intensão é outra, a procura concentra-se na reprodução da prosódia na repetição vocálica.

Examinemos a transcrição diplomática abaixo:

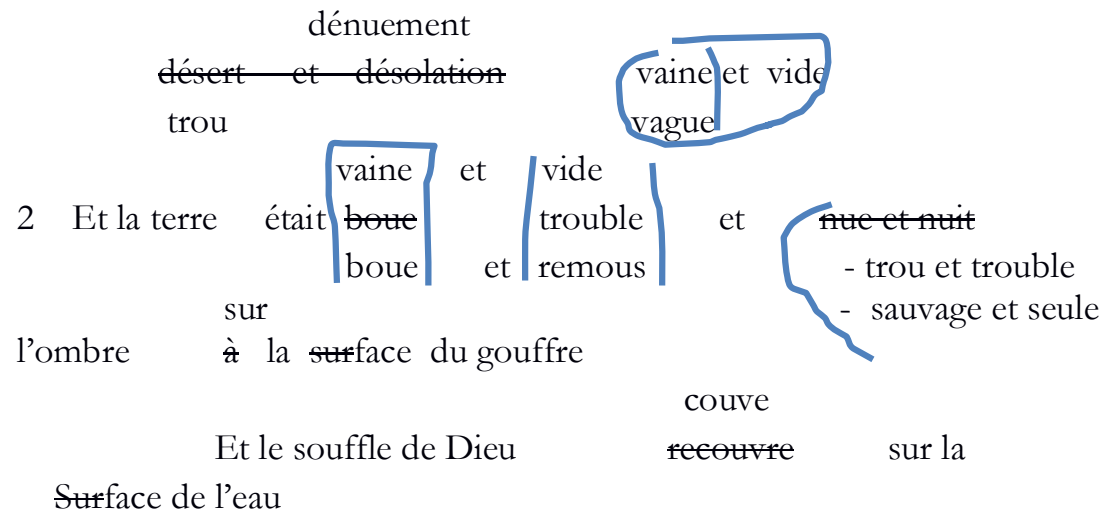

Transcrição diplomática do segundo versículo da segunda versão autógrafa

$\mathrm{Na}$ transcrição, é visível que o trabalho concentra-se na busca da prosódia que tornará audível o informe. Essa procura vê-se na lista dos pares de palavras visando organizar um encadeamento consonântico-vocálico, na repetição e no eco, criados por « vaine » e « vide » que, ao mesmo tempo em que são lidos e entendidos em seu sentido linguístico, o são também na significância criada pelo contínuo prosódico. Esse processo de criação passa pela escritura tradutória, assim como pela inscrição do sentido, que transborda o signo linguístico e refere-se ao movimento de leitura, que liga em um mesmo sopro « hayta tóhu », ou seja, o verbo e a primeira palavra do grupo, como explicado acima. Portanto, como o afirma Henri Meschonnic, desde sempre e em todos os seus escritos sobre tradução, não é a língua que deve ser traduzida, mas o texto escrito nessa língua. Ou seja, não são as palavras que devem ser traduzidas, mas o que elas fazem, isto é, a sua atividade. É exatamente o que constatamos nos manuscritos. 
Podemos ler na última versão: « Et la terre

प० était vaine

et vide $\square \square \square \square$ » e na publicação: «Et la terre était vaine et vide». ${ }^{33}$

Os símbolos e espaços brancos integram o processo de criação tradutório do ritmo, ao marcarem um sentido que não pode ser expresso em palavras. Esse recurso tipográfico é a singularidade que diferencia as traduções bíblicas de Henri Meschonnic.

(Gênesis, XI,1-9)

O segundo exemplo concerne ao episódio da Torre de Babel (Gênesis, XI-1-9). Para Henri Meschonnic (2010, p. 250) esse relato "é a cena primeva da teoria da linguagem, e da tradução". Abundantes notas acompanham a tradução e iniciam com a frase: "Le langage est ici l'atelier de Babel" 34 (MESCHONNIC, 2002a, p. 274), como uma metaforização do traduzirescrever. No acervo, encontrei versões datiloscritas com a data de 11/9/2001. No entanto, é provável que os datiloscritos datem de uma primeira fase de trabalho para a primeira publicação da tradução, em $1985^{35}$.

No datiloscrito, vemos que o versículo 7 não sofre modificação, enquanto os outros passam por uma intensa reescritura. Ele permanece nessa forma:

7

Allons descendons et là embabelons leur langue Qu'ils n'entendent pas l'un la langue de l'autre

O versículo 9 apresenta um trabalho de reescritura, contudo, as reescituras não tangem à criação do verbo embabeler que se repete no versículo:

\footnotetext{
33“E a terra era vã e vazia“.

34 “A linguagem é aqui o ateliê de Babel" (tradução nossa).

${ }^{35} \mathrm{O}$ texto foi publicado a primeira vez em Les Tours de babel, essais sur la traduction; em 1999 em Poétique du traduire e em 2002 em Au commencement; Traduction de la Genèse.
} 


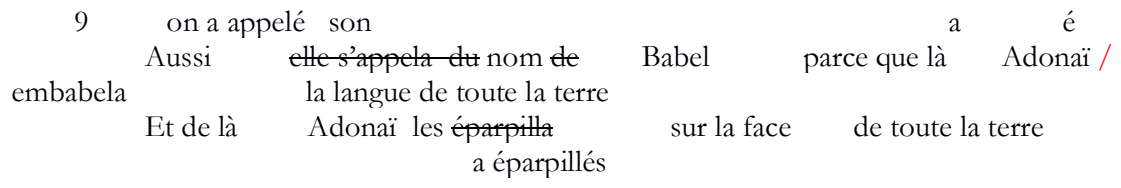

Dessa forma, « embabeler » (embabelar) é uma criação fixada desde a primeira publicação. O neologismo, mais uma vez, marca essa necessidade para o tradutor de traduzir o que o texto hebraico faz. Podemos ler no breve texto introdutório - que salienta a peculiaridade do episódio bíblico, o qual, além de ter uma temível simplicidade, é regido pelo calembur -, que a profusão de notas visa "mostrar a oralidade, comumente travestida em estilo escrito, e fazer o leitor entrar no ateliê destes problemas: os do texto são os da tradução, e os da tradução descobrem, ou ocultam os do texto" (MESCHONNIC, 2010, p. 252). Todo o trabalho de criação consiste em recriar o que texto faz (o calembur pela oralidade, na prosódia), ou seja, procura manter o sentido e a forma do sentido, somente possível na criação do neologismo. Esse calembur é preparado no versículo 7 « et là embabelons » (venavla cham. 'navla' vem do verbo 'balal' que significa emaranhar, confundir) e se completa, no versículo 9, com a repetição ('bavel' - Babel em hebraico, que tem sentido de confusão e de ruina) e «balal » (mesmo verbo). É significante o valor da onomatopeia formada pela repetição: navla-bavelbalal, a cadeia prosódica decorrente da organização das palavras nos versículos sustenta esse efeito (ba-bal-babil-que nos remete a balbulciar), e um sentido contido no nome da cidade (Babel), que já remete a confusão. O verbo (balal), é geralmente traduzido por "confundamos" ou "embaralhemos", isto é, geralmente reduzido à tradução do sentido da palavra, o que implica a perda do calembur. Sendo o calembur explicado em nota, isto é, com a forma separada do sentido. Com embabelar, a perda está varrida. Está acrescida a criação. E, o efeito se mantém.

\section{Atividade e Processo de Criação do Poema}

Vimos na análise de alguns exemplos concernentes à escritura ensaística que, desde pelo menos 1997, data inscrita no manuscrito (Poética do traduz̨ir), Henri Meschonnic instalou um processo de substantivação do verbo 
"traduzir". Nos dois exemplos de poemas a seguir permanece essa morfose substantivo-verbo, ponto nevrálgico do processo de criação meschonniciano. Para o poeta, um poema é "o que transforma a vida pela linguagem e a linguagem pela vida” (MESCHONNIC, 2006, p. 8). Daí o título do livro Vivre poème (Viver poema) no qual Henri Meschonnic ainda escreve: "le poète est poète quand il ne sait pas ce qu'il fait"36. (MESCHONNIC, 2006, p. 9).

Os poemas fazem parte do décimo livro de poemas ${ }^{37}$ de Henri Meschonnic. Lemos na primeira versão ${ }^{38}$ da última parte do poema:

Versão $1(24 / 25 / 26 / 2 / 1999)$

le visage

qui met son silence

dans ses bras

en dit plus

que celui qui pousse les mots

je continue de lentendre (sic)

la voix cachée est plus forte

elle ne s'arrêtera pas

la voix qui

se tait

s'ensilence est la plus forte
Versão 2 (25-26 février, 2 mars 1999)

le visage

qui met son silence dans ses

bras en dit plus que celui

qui pousse les mots

je t'entends je continue

de l'entendre la voix qui

s'ensilence est la plus forte

elle ne s'arrêtera pas

No manuscrito, vemos o ato de escritura entrar em ação, e em atividade, ou melhor dizendo, vemos o resultado (na rasura e no neologismo) desses dois movimentos. Na primeira versão foi suprimido « se tait » (se cala) e substituído na morfose que fez do « silence » (silêncio) o incoativo « s'ensilencer ». O verbo diz o movimento em direção ao silêncio ao mesmo tempo em que a reorganização do encadeamento prosódico produz uma atividade das palavras, distinta do sentido, que sugere um movimento. Algo está indo em algum lugar (pousse, ne s'arrête pas/empurra, não para). É a

\footnotetext{
36 “o poeta é poeta quando não sabe o que faz" (tradução nossa).

${ }^{37}$ Henri Meschonnic não dá títulos a seus poemas e não utiliza maiúscula inicial a cada nova linha. Este poema foi publicado no livro Tout entier visage. Paris: Arfuyen, 2005.

${ }^{38}$ Referência do document no IMEC: MCN 8.2.
} 
significância que se ouve no contínuo de «t'entends » (ouço), «l'entendre » (ouvir), « s'ensilence ». No eco dos « $t$ » e dos « 1 » que absorve e transforma o primeiro « silence » (na segunda linha) em movimento eternizado em direção ao silêncio. Esse efeito não acontecia na primeira versão. Notamos que as linhas ${ }^{39}$ foram reorganizadas para alongar o sopro da leitura. Essa tipografia participa da construção da significância, ela é uma maneira de significar que ultrapassa o semântico. É inegável dizer que houve reorganização de discurso, no movimento de escritura, entre a primeira e a segunda versão. Reorganização espacial do já escrito, organização do discurso que está-sendoinventando e que, segundo Henri Meschonnic, não está contando uma história, mas está fazendo emergir, na escritura, uma oralidade, algo de sujeito ${ }^{40}$ (o sujeito do poema), diferente do sujeito enunciador, e que se ouve no texto em devir e se ouvirá no texto publicado. A voz do escrito.

Meu propósito aqui não é a análise do modo de significar do poema, mas mostrar que as diversas versões não podem não guardar rastros do nascimento dessa atividade, primordial para Henri Meschonnic. Pois, ela é inerente à escritura em ato do sujeito que inventa o seu pensamento no deixar de sua presença no discurso que ele organiza, o que faz desse sujeito uma especificidade. Especificidade que se ouve. Portanto, a abordagem genética sustenta de forma eficiente um estudo que visa, não somente, compreender como foi feito o poema em suas várias etapas, como funciona o modo de significar do poema e como se constrói a atividade do sujeito do poema. Ou seja, a abordagem genética permite analisar o processo de criação do ritmo. Processo ao qual o texto publicado não dá acesso. No texto publicado pode-se estudar como funciona o ritmo de um texto, mas não o seu processo de criação.

\footnotetext{
${ }^{39}$ Henri Meschonnic utiliza linha e não verso.

${ }^{40}$ Henri Meschonnic fala em subjetivação, qualidade própria à invenção de um discurso por um sujeito e de um sujeito especifico pelo seu discurso. "É o sujeito do poema, qualquer que seja o gênero do texto. É distinto do indivíduo, do sujeito gramatical, do sujeito filosófico, psicológico, do sujeito do direito e do sujeito freudiano. A subjetivação de um discurso é a busca de uma semântica do contínuo independentemente do de seu funcionamento na língua" (MESCHONNIC, 2010, p. 236).
} 
Nesse outro exemplo de poema ${ }^{41}$, que faz parte da mesma coletânea, podemos ver que o processo de transformar substantivo em verbo, consequentemente em ação, deu-se no primeiro jorro de escritura, que permaneceu livre de modificações.

\section{Versão $1(16 / 3)$}

un visage

mais chaque visage

est la forme de ma vie

et je visage de toi

comme tu visages de moi

plus profond que toute la peau

jusqu'au dedans où les tristes

retrouvent

la matière

des joies
Versão $2(16 / 03 / 2001)$

un visage

mais chaque visage

est la forme de ma vie

et je visage de toi

? comme tu visages de moi plus profond que toute la peau jusqu'au dedans où les tristes retrouvent la matière des joies

A versão 2, passagem a limpo sempre feita com caneta tinteira preta, e sempre mencionando a data, é a versão que Henri Meschonnic entrega a Régine Blaig, esposa e colaboradora, para leitura e digitação. Vemos, na margem esquerda, que a marca em azul e o ponto de interrogação feitos pela colaboradora, apontam para uma singularidade que, por mais familiar que deva soar para ela, suscita, contudo, uma dúvida. Em resposta, no final da folha, Henri Meschonnic escreveu com caneta vermelha:

Ben oui quoi

Je transforme les noms en verbe

Faut que ça bouge ! ${ }^{42}$

Vemos, então, que as tensões que se manifestam no processo criativo repercutem tanto na produção ensaística quanto tradutória e poética. A criação

\footnotetext{
${ }^{41}$ Referência do documento no IMEC: MCN 8.2.

42 "Ben sim ora/ eu transformo as palavras em verbos/ tem de mexer" (tradução nossa).
} 
é uma só. Em 2006, no filme ${ }^{43}$ em que Henri Meschonnic fala de seu trabalho, ele diz a respeito do poema citado no último exemplo:

Je transforme les mots en verbes, ça s'imposait pour moi de transformer le mot visage en verbe. Ce n'est pas arbitraire. Je me demande si le travail poétique ne viserait pas, mais je sais bien que c'est une idée comme ça qui semble complètement irréaliste, à transformer les mots en verbe (rires). C'est-à-dire à agir sur le langage dans la mesure et seulement dans la mesure où on agit sur soi, sur soi-même par le langage et où alors le langage peut changer quelque chose à l'autre. $^{44}$

A partir dos diversos exemplos examinados, foi possível entrever o funcionamento do fazer criativo e do pensamento de Henri Meschonnic. Isto é, o sistema de sua escritura no qual não se dissociam o rítmico, o prosódico, o sentido e a forma, a vida e a criação. A atividade de sua escritura, aventura sempre vivida e movida em direção ao desconhecido, tem como cerne a maneira de escrever poemas. É ela que incide na sua maneira de traduzir, não o contrário. Henri Meschonnic teoriza e traduz como o poeta que ele é.

\section{Referências}

MESCHONNIC, H. Les cinq rouleaux. Paris: Gallimard, 1970.

MESCHONNIC, H. Pour la poétique II. Paris: Gallimard, 1973.

\footnotetext{
${ }^{43}$ Disponível em: < http://bit.do/dDtkb>. Acesso 31/10/2016.

44 'Transformo as palavras em verbos, para mim se impunha transformar a palavra rosto em verbo. Não é arbitrário. Eu me pergunto se o trabalho poético não visaria, mas sei que é uma ideia que parece completamente irrealista, transformar todas as palavras em verbos (risos). Isto é, agir na linguagem na medida em que, e somente na medida em que se age sobre si, sobre si-próprio pela linguagem e então a linguagem pode mudar algo no outro" (tradução nossa).
} 
MESCHONNIC, H. Critique du rythme. Paris: Verdier, 1982.

MESCHONNIC, H. Poétique du traduire. Paris: Verdier, 1999.

MESCHONNIC, H. Gloires. Traduction des Psaumes. Paris: Desclée de Brouwer, 2001.

MESCHONNIC, H. Au Commencement. Traduction de la Genèse. Paris:

Desclée de Brouwer, 2002.

MESCHONNIC, H. Les noms. Traduction de l'Exode. Paris: Desclée de Brouwer, 2003.

MESCHONNIC, H. Tout entier visage. Paris: Arfuyen, 2005.

MESCHONNIC, H. Vivre poème. Paris: Bernard Dumerchez, 2006.

MESCHONNIC, H. Poética do traduð̨ir. Tradução Jerusa Pires Ferreira; Suely Fenerich. São Paulo: Perspectiva, 2010.

VÉRITÉ de la Bible. L’infini, Paris, n. 76, p. 9-24, Automne 2001.

Enviado em: 16/11/2016

Aceito em: 20/12/2016 